\title{
Правовое обеспечение экологической безопасности при разработке морских нефтегазовых ресурсов Арктики
}

\section{Паничкин И.В.*}

В последнее время наблюдается бурный рост интереса к арктическим морским ресурсам нефти и газа, которые, предположительно, составляют до 30-40 \% всех неразведанных запасов нефти и газа в мире. Вместе с тем, аварии в процессе их разработки могут нанести непоправимый ущерб арктической экосистеме, а также иметь куда более глобальные последствия. В статье анализируется современное международно-правовое регулирование разработки данных ресурсов и рассматривается одно из направлений его развития, а именно - сотрудничество арктических государств в рамках международных организаций и форумов, создающих, так называемые, нормы «мягкого права». Также, уделяется внимание актам международных неправительственных организаций (профессиональных союзов, ассоциаций и т.д.). В заключение рассматриваются преимущества и недостатки использования норм «мягкого права» для регулирования разработки морских нефтегазовых месторождений Арктики.

Ключевые слова: Арктика; морские нефтегазовые ресурсы; недоговорные нормы.

Авария в Мексиканском заливе продемонстрировала, какую опасность представляет собой разработка глубоководных нефтегазовых ресурсов. В Арктике, подобные аварии - в условиях пониженных температур, дрейфующих и патовых льдов, а также отсутствия развитой необходимой инфраструктуры, обеспечивающей незамедлительное реагирование на чрезвычайные ситуации, - будут иметь куда более серьезные последствия не только для ее окружающей среды, но и для экономики всех арктических государств. Учитывая, что Арктика имеет биосферное и климатообразующее значение для всего Земного шара, и изменения в Арктике могут нарушить циркуляцию океанических

\footnotetext{
* Паничкин Иван Витальевич - аспирант кафедры правового регулирования ТЭК Международного института энергетической политики и дипломатии МГИМО (У) МИД России. Ivan_pan@mail.ru.
} 
течений в мировом океане 1 , становится очевидным, что последствия аварии в этом регионе могут иметь глобальный характер. В этой связи, некоторые специалисты даже придерживаются той точки зрения, что негативные последствия аварий в Северном ледовитом океане столь велики, что, возможно, осуществление опасных видов деятельности (к которым относится и нефтегазодобыча) в этом регионе нецелесообразно ${ }^{2}$. Эту точку зрения подкрепляют исследовательские данные, свидетельствующие, например, о том, что технологий, которые бы гарантировали сбор нефти в покрытых льдом районах, в настоящее время не существует ${ }^{3}$. Однако, учитывая, что энергетическая и транспортная системы в Арктике будут и дальше развиваться, неся при этом угрозы арктической экосистеме, многие ученые и исследователи задаются вопросом - насколько современное международное право способно обеспечить экологическую безопасность ${ }^{4}$ арктической экосистемы при разработке ее морских нефтегазовых месторождений 5 .

${ }^{1}$ Вылегжанина Е.Е.. Современные международно-правовые основы и перспективы сохранения арктической экосистемы // Охрана окружающей среду и природопользование. № 2 2009. С. 20-25; С. Mauritzen, Arctic impact on global ocean circulation // The Circle, no. 3.2009. P. 11.

2 Dennis Takahashi-Kelso. Oil spill on ice not worth the risk // электрон. Интернет-журн. 2010. 14 мая. URL: http://blogs.reuters.com/environment/2010/05/14/oil-spill-on-ice-notworth-the-risk/ (дата обращения 10.09.2010)

${ }^{3}$ CM.: Advancing Oil Spill Response in Ice-Covered Waters. Report by "Prince William Sound Oil Spill Recovery Institute Cordova, Alaska" and "United States Arctic Research Commission Arlington".

4 Под экологической безопасностью понимается одна из составляющих национальной безопасности, совокупность природных, социальных и других условий, обеспечивающих безопасную жизнь и деятельность проживающего (либо действующего) на данной территории населения (Хуршудов А.Г.) Концепция экологической безопасности ресурсной северной территории // Биологические ресурсы и природопользование. -1997. -Вып. 1. -С. 87-98.) и обеспечение устойчивого состояния биоценоза естественной экосистемы (Большеротов А.Л. Система оценки экологической безопасности строительства. - М.: Издательство Ассоциации строительных вузов, 2010. - C. 216).

5 Is it high time for a tough Arctic treaty? By Ed Struzik // Edmonton Journal: электрон. журн. 2010. 27 июня. URL: http://www.edmontonjournal.com/news/high+time+tough $+\mathrm{Ar}$ ctic+treaty/3207557/story.html (дата обращения 13.09.2010); Whither the Arctic? Conflict or cooperation in the circumpolar north, Oran R. Young. Polar Record (2009), 45 : 73-82 Cambridge University Press; Russia and the Arctic: Opportunities for Engagement Within the Existing Legal Framework, Michael A. Becker, American University International Law Review (2009), volume 25, issue 2, p. 225-476; Timo Koivurova, "Alternatives for an Arctic Treaty-Evaluation and a New Proposal," RECIEL 17 (1), 2008: 14-26; Skjærseth J B, 
К разработке энергетических ресурсов Арктики применимо большое количество международных договоров, в частности: Соглашение между Данией, Финляндией, Исландией, Норвегией и Швецией об оповещении и сотрудничестве в случае загрязнения моря нефтью или другими опасными веществами 1993 г.; Соглашение между Данией и Канадой о сотрудничестве в отношении охраны морской среды 1983 г.; Конвенция о защите морской среды северо-восточной части Атлантического океана 1992 г;; МАРПОЛ; Лондонская конвенция 1972 г. и др.

Конвенция ООН по морскому праву 1982 года ${ }^{6}$, содержит, как известно, специальную статью, имеющую прямое отношение к Арктике, Ст. 234 «Покрытые льдом районы». Однако ее действие ограниченно пределами исключительной экономической зоны.

На прошедшей в 2008 году Конференции по вопросам Северного Ледовитого океана (г. Илулиссат, Гренландия), арктические государства заявили, что «в отношении Северного Ледовитого океана применяется обширная межнународно-правовая база... Поэтому мы не видим необходимости в разработке нового всеобъемлющего международно-правового режима для управления Северным Ледовитым океаном». Они также выразили готовность «предпринимать шаги в соответствии с международным правом, как на национальном уровне, так и в рамках сотрудничества между пятью государствами и другими заинтересованныли сторонами для обеспечения защиты и сохранения хрупкой морской среды Северного Ледовитого океана... работать вместе, в том числе в рамках Международной морской организации в целях укрепления существующих мер и разработки новых мер, направленных на повышение безопасности морского судоходства и предотвращение или снижение риска загрязнения с судов Северного Ледовитого океана» ${ }^{7}$.

Stokke O S and Wettestad J. Soft law, hard law, and effective implementation of international environmental norms. Global Environmental Politics 2006;6:104-20.

${ }^{6} \mathrm{~B}$ отечественной и зарубежной литературе существуют различные точки зрения в отношении того, насколько применима Конвенция 1982 г. к Арктике. - См. Международное право. Предисловие С.В. Лаврова. Ред. колл. Вылегжанин А.Н., Колосов Ю.М., Малеев Ю.Н., Колодкин Р.А. С. 193-205.

7 Декларация Конференции по вопросам Северного Ледовитого океана, Илулиссат, Гренландия, 27-29 мая 2008 года //интернет сайт МИД РФ. 29 мая 2008. URL:http:// www.mid.ru/brp_4.nsf/76bbf733e3936d4543256999005bcbb7/986b338f469167da5c32574 58004581 fe?OpenDocument (дата обращения 14.09.2010). 
Вместе с тем, одной из особенностей современного международно-правового регулирования, применимого к разработке морских нефтегазовых ресурсов Арктики, является то, что оно сосредоточено, в основном, на общих вопросах, таких как: обязательство защищать и сохранять морскую среду; обязательство принимать меры по предотвращению, сокращению и сохранению под контролем загрязнения морской среды; обязательство принимать все возможные меры для предотвращения загрязнения моря сбросами отходов и других материалов, которые могут представить опасность для здоровья людей, повредить живым ресурсам и жизни в море и т.д.

Большая же часть практических вопросов рассматривается на национальном уровне. Это приводит к тому, что, в зависимости от технологических, экономических и других возможностей того или иного приарктического государства, ими предъявляются различные требования к компаниям, желающим разрабатывать их морские нефтегазовые ресурсы. Учитывая же масштабность и трансграничный характер последствий возможных аварий, представляется, что объективно востребована гармонизация и выработка единообразных стандартов, правил и требований в целях обеспечения экологической безопасности разработки морских нефтегазовых ресурсов Арктики. Одним из подходящих механизмов для этого могут служить международные организации и межправительственные форумы, в рамках которых разрабатываются недоговорные акты ${ }^{8}$. Они представляют собой решения и рекомендации, не являющиеся обязательными, носящие факультативный характер. Кроме того, такая работа может проводиться и в рамках международных неправительственных организаций, в частности, профессиональных ассоциаций и союзов, которые разрабатывают отраслевые стандарты в нефтегазовой отрасти.

К международным организациям, в рамках которых происходит сотрудничество, в том числе и арктических государств, и создаются недоговорные нормы, можно отнести, в первую очередь, Международную морскую организацию (далее ИМО). В рамках ИМО были разработаны многочисленные рекомендации и Руководства, касающиеся разработки морских нефтегазовых ресурсов, а также транспортировки нефти и газа, в частности: Руководство по разработке судовых планов чрезвычайных мер по борьбе с загрязнением моря нефтью и (или)

${ }^{8}$ В иностранной научной литературе используется термин «мягкое право» (англ. softlaw). 
вредными жидкими веществами; Правила постройки и оборудования судов, перевозящих сжиженные газы наливом; Руководство и спецификации по системам автоматического замера, регистрации и управления сбросом нефти для нефтяных танкеров; Кодекс постройки и оборудования плавучих буровых установок; Руководство и стандарты по удалению морских установок и сооружений на континентальном шельфе и в исключительной экономической зоне; Руководство по назначению специальных районов и определение особенно чувствительных с точки зрения загрязнения моря и другие.

Применительно именно к арктическим условиям в ИМО было разработано специальное «Руководство для судов, осуществляющих деятельность в покрытых льдом водах Арктики» (Руководство по судоходству в Арктике). Данное Руководство охватывает широкий круг вопросов, связанных с арктическим судоходством. Поводом к разработке данного Руководства послужила аварии танкера Exxon Valdez ${ }^{9}$, которая показала, что национальное законодательство, пусть даже наиболее развитое, не создает адекватной правовой основы для предотвращения подобного рода аварий. Проведенный после данной аварии анализ национальных законодательств приарктических государств показал: они содержат существенные различия в технических требованиях для навигации в Арктике, это может привести к тому, что морское судно, плавающее в водах Арктики, будучи допущенным в порты одного арктического государства, может не быть допущено в порты другого арктического государства. Поэтому, международным сообществом было принято решение о гармонизации национальных правил и разработке стандартов безопасной арктической навигации на международном уровне. Комитет по защите морской среды на своей 48-ой сессии (октябрь 2002) и Комитет по безопасности на море на 76-ой сессии (декабрь 2002), одобрили данное Руководство ${ }^{10}$. А в 2009 году была одобрена его новая редакция ${ }^{11}$.

9 Exxon Valdez - танкер, потерпевший аварию 24 марта 1989 на побережье Аляски в проливе Принца Вильгельма, который, географически, не относится к Арктике, однако имеет схожие климатические условия. В результате аварии произошла утечка нефти, которая привела к экологической катастрофе в регионе.

${ }^{10}$ Øystein Jensen. The IMO Guidelines for Ships Operating in Arctic Ice-covered Waters. FNI Report 2/2007. P. 9.

${ }^{11}$ Ships operating in Polar regions // интернет сайт Международной морской организации IMO.org. URL: http://www.imo.org/Newsroom/mainframe.asp?topic_id=1773\&doc_ $\mathrm{id}=11041$ (дата обращения 15.09.2010). 
Руководство по судоходству в Арктике включает только те положения, которые еще не урегулированы международными договорами или недоговорными актами, и не ставит целью выходить за рамки национальных систем регулирования судоходства. Данное Руководство было разработано не как самостоятельный документ, а как дополняющий такие международные договоры как: Международная конвенция по охране человеческой жизни на море (СОЛАС), Международная конвенция по предотвращению загрязнения с судов (МАРПОЛ), Международная Конвенция по Стандартам Обучения, Сертификации и Вахтенной Службы Моряков и Международный кодекс по управлению безопасной эксплуатацией судов и предотвращением загрязнения. Все эти документы в равной степени применимы и к арктической навигации 12 .

Данное Руководство регулирует такие вопросы, как: проектирование судов; оснащение судов; эксплуатация судна, включая вопросы спасательного оснащения. В нем есть специальный раздел, в котором даются определения основных понятий, используемых в Руководстве, среди которых: «Чистые ото льда воды» (Ice-Free Water); «Судно полярного класса» (Polar Class Ship); «Загрязнитель окружающей среды» (Pollutant); «Полярные воды» (Polar Waters) и другие. Важным аспектом, затрагиваемым Руководством является введение классификации судов. Так, Руководство различает суда Арктического класса (Polar class) и суда неарктического класса (Non-Polar class); к последним применяются только Части В и С Руководства. Суда арктического класса классифицируются на 7 классов (данная классификация заимствована из классификации Международной Ассоциации Классификационных Обществ (МАКО)).

На сегодняшний день данное руководство не было имплементировано в законодательство какого-либо государства, однако, оно активно используется, например, в Норвегии, где применяется навигационными инструкторами в качестве учебного пособия ${ }^{13}$.

В рамках Арктического Совета также разрабатываются акты рекомендательного характера, касающиеся безопасности разработки арктических нефтегазовых месторождений.

Одним из наиболее значимых Руководств, принятых Арктическим Советом, является «Руководство по освоению месторождений нефти и газа в море» (Руководство), которое было принято в 1997 г и обновлено

12 Øystein Jensen, p. 10.

${ }^{13}$ Øystein Jensen. p. 21. 
в $2002^{14}, 2007^{15}$ и 2009 гг. ${ }^{16}$ Как сказано в Преамбуле, его одобрение является выражением единого понимания минимально необходимых действий по защите морской среды Арктики от нежелательных экологических последствий, вызываемых проведением морских нефтяных и газовых работ. Руководство включает ряд практических рекомендаций, касающихся разработки месторождений нефти и газа на арктическом шельфе ${ }^{17}$, включая транспортировку и связанную с освоением месторождений деятельность на суше. Рекомендации адресованы соответствующим национальным органам, а также энергетическим компаниям для использования на всех этапах планирования программ разработки нефтегазовых месторождений на шельфе, проведения геологоразведочных работ, эксплуатации месторождений и прекращении разработки. В Руководстве раскрывается содержание принципов, на которых должна основываться деятельность по разработке нефтегазовых ресурсов арктического континентального шельфа: принцип «осторожного подхода» (англ. - Principle of the Precautionary Approach); принцип «загрязняюший платит» (англ. - Polluter Pays Principle); принцип «постоянного улучшения» (англ. - Continuous improvement); принцип «устойчивого развития» (англ. - Sustainable Development).

В Руководстве рассматривается влияние нефтегазовой деятельности на окружающую среду, на проживающих в регионе местных и иных жителей, при этом отмечается, что в ходе планирования и осуществления нефтегазовой деятельности необходимо принимать меры к сохранению памятников культуры, учету традиционных знаний местных народов $^{18}$. Данное Руководство охватывает все этапы морских нефтяных и газовых работ. Особое значение уделено оценке воздействия на окружающую среду, мониторингу окружающей среды и правилам технической эксплуатации. В приложении E (Annex E) приводятся примеры процессов оценки ОВОС в таких странах как Норвегия, США, Канада, Россия и Дания.

\footnotetext{
${ }^{14}$ CM.: http://www.pame.is/images/stories/PDF_Files/Doc_lib/OffshoreOilandGas_/2002g uidelines-Russian.pdf.

15 См.: http://www.pame.is/images/stories/FrontPage/Offshore_Oil_and_Gas/Summary_ from_Workshop_dec_072.pdf

${ }^{16}$ CM.: http://www.pame.is/images/stories/FrontPage/Arctic-Guidelines-2009-13th-Mar2009. pdf.

${ }^{17}$ Имеется в виду арктический шельф в геологическом понимании.

18 Е.Е. Вылегжанина. С. 23.
} 
Кроме этого, Арктическим Советом были приняты следующие Руководства: «Руководство по перекачке очищенной нефти и нефтепродуктов в водах Арктики» ${ }^{19}$; «Руководство по безопасной транспортировке нефти в арктических водах» 20 ; «Практическое Руководство по ликвидации последствий нефтяных разливов в арктических водах» ${ }^{21}$.

Различного рода рекомендации, касающиеся экологически безопасного использования месторождений нефти и газа в Арктике, разрабатываются, как уже отмечалось выше, также и международными неправительственными организациями (профессиональными ассоциациями и союзами). Помимо формулирования отраслевых стандартов, такие организации - не редко совместно с межправительственными организациями - разрабатывают Руководства и справочники, содержащие рекомендации в отношении применения существующих международных договоров и их имплементации на уровне национального законодательства.

Среди наиболее известных организаций такого рода можно выделить следующие: Международный морской форум нефтяных компаний $^{22}$ (ММФНК, англ. OCIMF), имеющая статус консультанта в ИМО; Международная палата судоходства и Международная федерация судоходства ${ }^{23}$ (МПС и МФС, англ. ICS и ISF); Международная ассоциация производителей нефти и газа 24 (МАПНГ, англ. OGP); Международная ассоциация представителей нефтяной промышленности по охране окружающей среды ${ }^{25}$ (англ. IPIECA); Международная федерация владельцев танкеров по предотвращению загрязнения ${ }^{26}$ (МФВТПЗ, англ. ITOPF); Международная Ассоциация Классификационных Обществ (МАКО, англ. IACS) и другие.

В целом, как представляется, акты рекомендательного свойства играют существенную роль в правовом обеспечении экологической безопасности эксплуатации арктических энергетических ресурсов. В них на высоком уровне проработано большое количество практических

${ }^{19}$ Cм.: http://www.pame.is/images/stories/PDF_Files/Doc_lib/OilandGasReports/ TROOP\%20-\%20Russian\%202.pdf.

${ }^{20} \mathrm{C}$.: http://old.pame.is/sidur/uploads/oilandgasguidelines.PDF.

${ }^{21}$ См.: http://eppr.arctic-council.org/content/fldguide/index.html.

${ }^{22}$ Cм.: http://www.ocimf.com.

${ }^{23}$ См.: http://www.marisec.org/.

${ }^{24}$ Cм.: http://www.ogp.org.uk/index.html.

${ }^{25}$ См.: http://www.ipieca.org.

${ }^{26}$ CM.: http://www.itopf.com/. 
аспектов освоения морских нефтегазовых месторождений Арктики, а также транспортировки нефти и газа с учетом особенностей региона, его специфики и значения. Как представляется, можно говорить о том, что рассмотренные недоговорные акты содержат минимальные стандарты, правила и требования, соблюдение и исполнение которых всеми арктическими государствами могло бы снизить риск аварий или иных чрезвычайных ситуаций, способных нанести ущерб арктической экосистеме или привести к человеческим жертвам. Несмотря на необязательный характер такого рода актов, их влияние на деятельность соответствующих субъектов достаточно высоко. Государства, хотя и не полностью реализуют содержащиеся в них рекомендации, но, тем не менее, учитывают их существенным образом. Соблюдение и эффективность, как отмечают некоторые авторы, в данном случае, имеют «обратную связь» 27.

Кроме того, использование арктическими государствами недоговорных актов позволяет избежать тех сложностей, в том числе и политического характера, которые часто возникают при разработке международных договоров.

\section{Библиографический список}

Буник И.В. Правовые особенности транспортировки арктических углеводородов (российское, канадское, международное право): статья // Московский журнал международного права. - Специальный выпуск декабрь 2005. - Энергетика и право: правовой режим природных ресурсов.

Вылегжанина Е.Е.. Современные международно-правовые основы и перспективы сохранения арктической экосистемы // Охрана окружающей среду и природопользование. № 22009.

Вылегжанин А.Н. Международное право: учебник. - М.: Высшее образование, Юрайт-Издат, 2009.

Колодкин А.Л., Гуцуляк В.Н., Боброва Ю.В. Мировой океан. Международно-правовой режим. Основные проблемы. - М.: Статут, 2007.

Abbott, Kenneth W, and Duncan Snidal, 2000. Hard and Soft Law in International Governance. International Organization, 54.

C. Mauritzen, Arctic impact on global ocean circulation // The Circle, no. 3.2009.

${ }^{27}$ David G. Victor, Kal Raustiala and Eugene B. Skolnikoff. P. 686. 
David Armstrong. Routledge handbook of international law. 2009.

David G. Victor, Kal Raustiala and Eugene B. Skolnikoff. The Implementation and Effectiveness of International Environmental Commitments: Theory and Practice. Laxenburg Austria. Cambridge Mass.: International Institute for Applied Systems Analysis. MIT Press.

Dennis Takahashi-Kelso. Oil spill on ice not worth the risk // электрон. интернет-журн. blog.reuters.com.

Ed Struzik. Is it high time for a tough Arctic treaty? Edmonton Journal: электрон. журн.

John B. Bellinger, Treaty On Ice, N.Y. TIMES, June 23, 2008, at A21.

Kal Raustiala. Form and Substance in International Agreements // American Journal of International Law. Vol. 99. July 2005.

Natalia Loukacheva. Polar Law Textbook. Nordic Council of Ministers, Copenhagen 2010.

Martin Köppel. Explaining the Effectiveness of Binding and Nonbinding Agreements. Tentative Lessons from Transboundary Water Pollution. Paper prepared for the 2009 Amsterdam Conference on the Human Dimensions of Global Environmental Change, 2-4 Dec 2009 Architecture, Panel 7: Understanding Multilateral Environmental Agreements as Governance Mechanisms.

Michael A. Becker. Russia and the Arctic: Opportunities for Engagement Within the Existing Legal Framework, American University International Law Review (2009), volume 25, issue 2.

Oran R. Young. Whither the Arctic? Conflict or cooperation in the circumpolar north, Polar Record (2009), 45. Cambridge University Press.

Øystein Jensen. The IMO Guidelines for Ships Operating in Arctic Icecovered Waters. FNI Report 2/2007.

Rob Huebert, "New Directions in Circumpolar Cooperation: Canada, the Arctic Environmental Protection Strategy and the Arctic Council," Canadian Foreign Policy 5, no. 2 (Winter 1998).

Skjærseth J B, Stokke O S and Wettestad J. Soft law, hard law, and effective implementation of international environmental norms. Global Environmental Politics, 2006, № 6.

Timo Koivurova, "Alternatives for an Arctic Treaty-Evaluation and a New Proposal,” RECIEL 17 (1), 2008. 


\section{Development of Legal Regulation of Arctic Marine Oil and Gas Resources: Soft-law Approach (Summary)}

\section{Ivan V. Panichkin*}

In recent years there has been seen rapid growth of interest in the Arctic marine oil and gas, which supposedly constitute $30-40 \%$ of the world's undiscovered oil and gas resources. At the same time, accidents, which could take place while developing of the resources, can not only cause irreparable injury to the Arctic ecosystem, but have global consequences. This article analyzes current international law regulating the development of the Arctic marine oil and gas resources and examines one of the directions of its development - cooperation amount the Arctic States in international organizations and forums, creating "soft-law" rules. The article also considers to acts of international non-governmental organizations (unions, associations and etc.). In conclusion, the article analyzes the advantages and disadvantages of using of the "soft-law approach" to regulate the development of the Arctic marine oil and gas resources.

Keywords: the Arctic; marine oil and gas resources; "soft-law".

\footnotetext{
* Ivan V. Panichkin - post-graduate student of the International institute of Energy Policy and Diplomacy, MGIMO-University MFA Russia. Ivan_pan@mail.ru.
} 